\title{
FLOOD FORECASTING METHOD BASIS AS FLOOD MONITORING PROGRESS OF MEKONG RIVER
}

\author{
Guoping CHEN ${ }^{1,2}$, Wenzhao RUAN ${ }^{2 *}$, Junsan ZHAO $^{2}$ \\ ${ }^{1}$ Geomatics Engineering Faculty, Kunming Metallurgy College, NO.388Xuefu Road, Kunming 650033, China - 115432640@qq.com \\ ${ }^{2}$ Faculty of Land Resource Engineering, Kunming University of Science and Technology, No.68 Wenchang Road, 121Street, \\ Kunming 650093, China-115432640@qq.com
}

\section{Commission III, WG III/8}

KEY WORDS:MODIS,EVI,LSWI, flood monitoring, Mekong river basin

\begin{abstract}
:
In this paper, used MODIS satellite image (MOD13) for monitoring the progress of flood in Mekong River Basin and testing the flood forecasting method for the Mekong Delta in flooding stage of 2015. The results showed that ( $80 \%$ reliability): MODIS image can be used to monitor the progress of flood in large areas of the Mekong River Basin. There was a close relationship between enhanced vegetation index EVI, land surface water index LSWI with growth status of plants and surface water of the flood. Risk flood maps during the flood season of the study area were established as the basis for developing the flood forecasting method applied to the Mekong Delta. With accuracy about 91\%, this flood forecast method opened a new direction for researching about environmental disasters using the resource of satellite image at low cost. Therefore, it should use these images for monitoring the process, forecasting flood capability and other related fields in combination with other types of vegetation indices.
\end{abstract}

\section{INTRODUCTION}

In recent years, due to the effects of climate change, Mekong Delta (MRD) has experienced several major floods, most of which are caused by the floods from Mekong upstream(LV,et al., 2014; K., et al., 2010). Therefore, the meteorological and hydrologic prediction agencies shall take practical measures to making forecasts of flood possibility, so that people can prevent or minimize the damages to people and properties. The remote sensing image technology is a tool used to track, monitor and support the flood prediction. Currently, there are many researches for its application of the flood prediction model in the Mekong Delta(ZHONG, et al., 2011;ZHEN, et al., 2011;XIE, et al., 2016). However, monitoring methods and this model require the data and complex computations and are constrained by many factors such as flow cycle, flow direction and upstream floods. Through using multispectral- multi-time MODIS remote sensing images provided by NASA in combination the DEM (Digital Elevation Model), the progress of the Mekong River Basin Flood can be monitored as the basis for flood prediction at Mekong Delta.

The research was conducted with the aim of: (1) Evaluating the possibility of using the multi-time MODIS images to monitor the progress of Mekong River Basin floods; (2) Proposing the solutions to forecasting the Mekong Delta flood progress in the flooding period in 2015 .

\section{DATA AND METHODOLOGY}

\subsection{Data}

\subsubsection{Multi-time MODIS/ TERRA image data}

Use the MODIS/TERRA SURFACE REFLECTANCE 8-DAY L3 GLOBAL 500 M SIN GRID V005 (MOD13) satellite images (MOD13) with a temporal resolution of 8 days and spatial resolution of $500 \mathrm{~m}$ (PENG, et al., 2004;ZHAO, et al., 2012). The images have been collected from the data system of the NASA Earth observation (EOS, 2013) in the period of 2013 to the first half of 2015; Use the Band 1,2, 3 and 6 (red, near infrared and infrared short wave etc) to calculate the EVI, LSWI and DVEL indexes as the basis for the analysis and evaluation of the results.

\subsubsection{SPOT Imagery Data}

SPOT 5 images with a resolution of $80 \times 80 \mathrm{~m}$ and 3 Red Green - Blue bands are collected from Singapore Remote Sensing Center (CRIPSs) to be used for comparing and inspecting the results interpreted from MODIS.

\subsubsection{DEM digital elevation map of the research area}

DEM Digital Elevation Model of Mekong River Basin collected from the ERSDAC Center of Earth Data Analysis in Japan (http://www.gdem.aster.ersdac.or.jp/) to be used to evaluate the flow direction of the river systems on the topographic forms of research areas. The model is calculated on the basis of elevation, slope and flow direction indexes to define the direction of river flows. 


\subsection{Research Methodology}

\subsubsection{Flood mapping methods}

The method of Sakamoto et al. is proposed to assess the flood. If the EVI value is greater than 0.2 , it will be considered as opaque pixels covered by clouds and will be removed from the image (Thenkabail, et al., 2005; Xiao, et al, 2006). According to Xiao, et al. $(2005,2006)$, if the EVI value is greater than 0.3, the object is classified as a pixel without flood. If the EVI value is $\leq 0.05$ and less than or equal to 0 , the pixel will be defined as relevant water pixels.

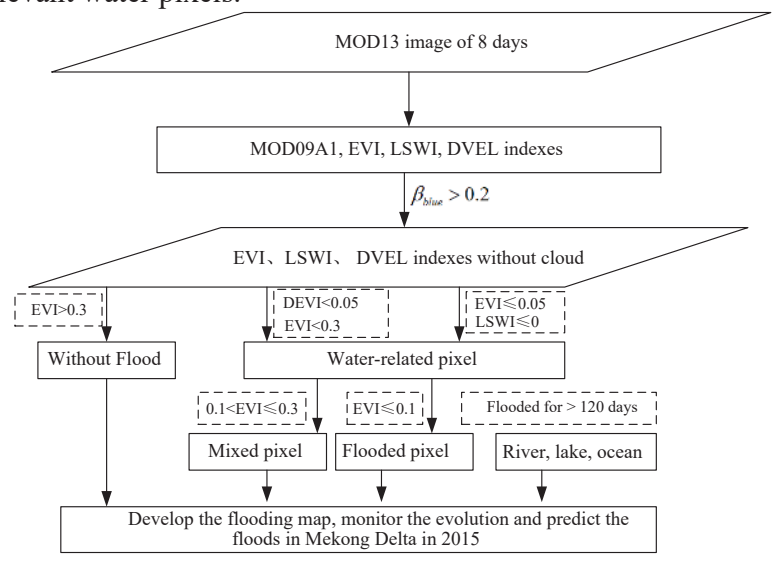

Fig.1 Methods for monitoring the progress and predicting floods for Mekong Delta by MODIS (Source: Sakamoto et al, 2007)

Then, it is necessary to classify into flooding pixel, combined pixel or long-term submerged objects. If the water-related pixel has EVI $<0.1$, it is considered as a flooding pixel. If the EVI value is greater than 0.1 but less than 0.3 , the water-related pixel is identified as a combined pixel. The constantly flooded area is constantly being separated from the flood and mixed pixel. The pixel involves water flooding time $>120$ days will be classified as long-term submerged object.

\subsubsection{The flood progress predicting methods}

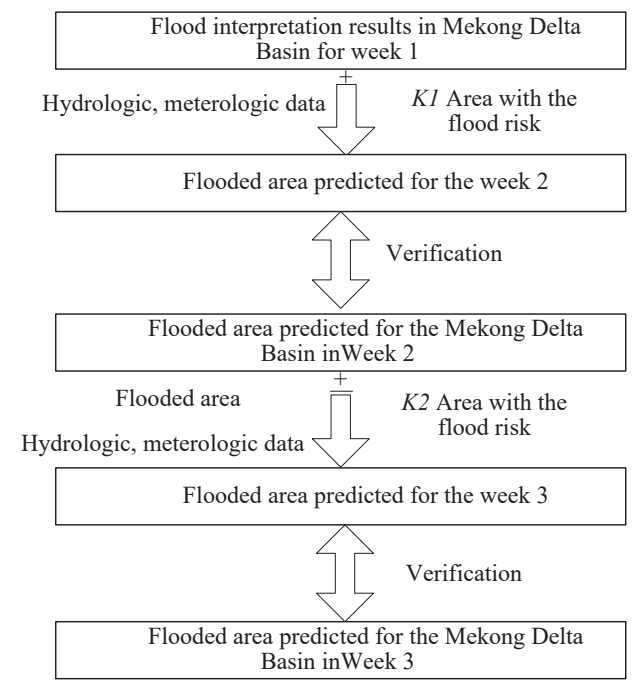

Fig.2 Methods of predicting the possibility of flooding in the

$$
\text { Mekong Delta }
$$

1 Average increase (decrease) coefficient $k=D T$ flooding risk of week 1/ Increased (Decreased)DT of week 2 compared to week $1=0.02$ is selected as a value with the highest frequency of appearance in the calculation results $k 1, k 2, k 3 \ldots k n$ results from interpretation of the images in the flood season of 2013 to 2014. The $(+)$ mark corresponds to the starting stage of flood season and the (-) mark corresponds to the ending stage of flood season.

To predict the flood progress for a week later, use a set of photos taken at the present time, the interpretation results are analyzed and assessed in conjunction with the data of velocity, flow directions from DEM, the meteorological and hydrologic data for predicting and determine the area and the distribution of flooded space for the following weeks. The prediction results of last week will be verified by the image interpretation results of the following weeks. The interpretation results of the current images on the flooded area, the area at risk of flooding in combination with the collected meteorological and hydrologic data are used to make predictions to the flooding progress in a week later.

\section{RESULTS OF DISCUSSION}

\subsection{Flooding progress of research area}

\subsubsection{The distribution of submerged spaces in the research area}

Based on the classification of objects by a combination of EVI, LSWI and DVEL indexes, series of photographs showing the flood distribution throughout the flood season of 2013, 2014 and 2015 are collected. The comparison of flooded areas over the years shows the trend of flood progress as the basis for determining the time at which the flooded area is increased dramatically (flood occurrence) to the maximum level (flood peak) and the start of reduction (flood withdrawal).

The interpretation results show that since 20th July 2013, the flood has advanced to the upstream provinces of Mekong Delta. The progress at the same time for 2014 and 2015 was 21 st August and for 2015 was 5th August. Since 05th August 2015, the flood has begun to increase rapidly due to the rain and storms in the middle and downstream area as well as Mekong River flood-tides. The flood reached the flood peak in the first half of October for 2013 and in the late October to early May 11 for 2014. The flood in 2015 increased rapidly and reached its peak at the end of October. The floods in 2013 and 2014 started withdrawing at the end of November or early December and completely withdrew at the end of December. 


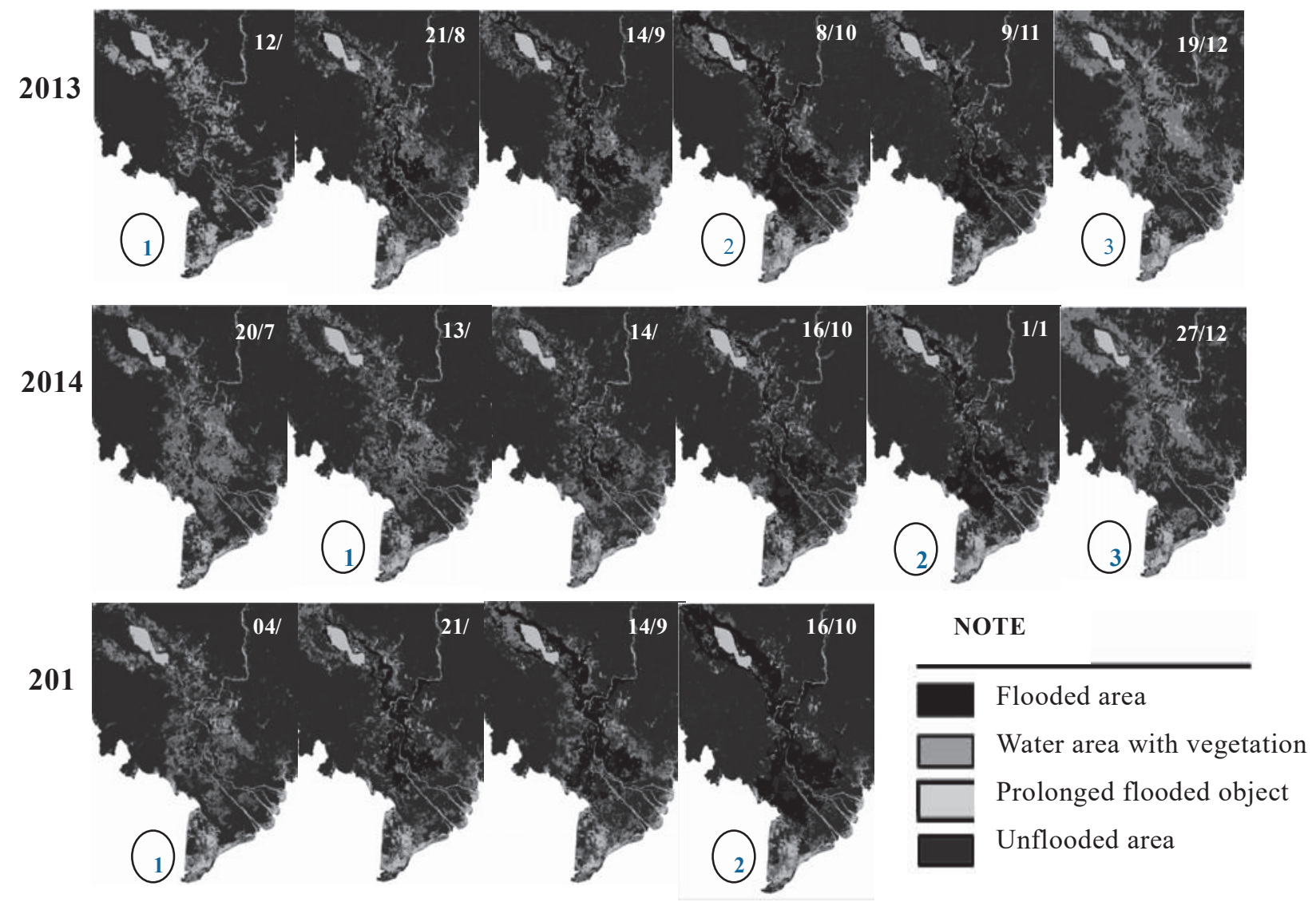

Fig.3 The progress of floods in Mekong Basin over the years

\subsubsection{The change in the flooded area of Mekong}

\section{River Basin}

Generally, the floods over years are similar. The water surface area is about $10,000 \mathrm{~km} 2$ and relatively stable in dry season and experiences the great changes from the early July; however, the flooding levels are different over years. If the flood season in 2014 had a sign of decreasing compared to 2013, the flood in 2015 has increased equal to or more than 2013. In the Mekong Delta, the flood in 2013 started on around 20th July 2013

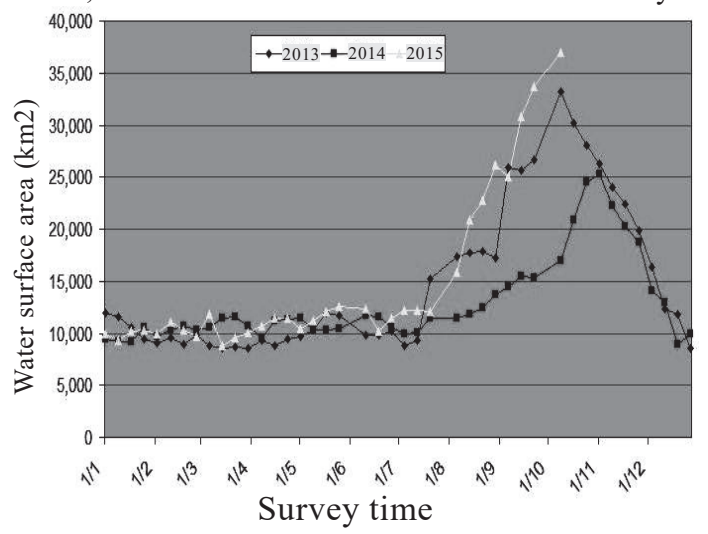

and until early December 2013 then gradually withdrew. The total flooded area in the flood season from early July to the end of December was estimated at $460.254 \mathrm{~km} 2$, for 2014 at about $317053 \mathrm{~km} \mathrm{2,} \mathrm{while} \mathrm{the} \mathrm{flood} \mathrm{in} 2015$ reached $248643 \mathrm{~km} 2$, since the beginning of the flood season to the end of September of the same year and gradually increased at the end of October.

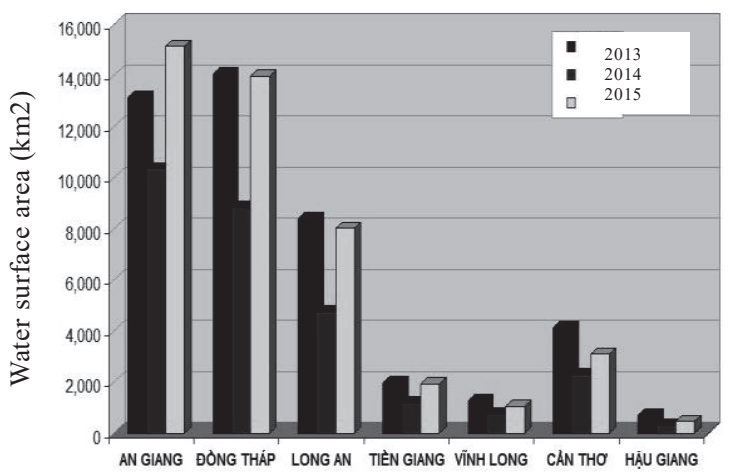

Mekong Delta provinces

Fig.4 The changes in the flooded area of basin and some Mekong Delta provinces over the years 


\subsubsection{Compare the interpretation results with the monitoring data}
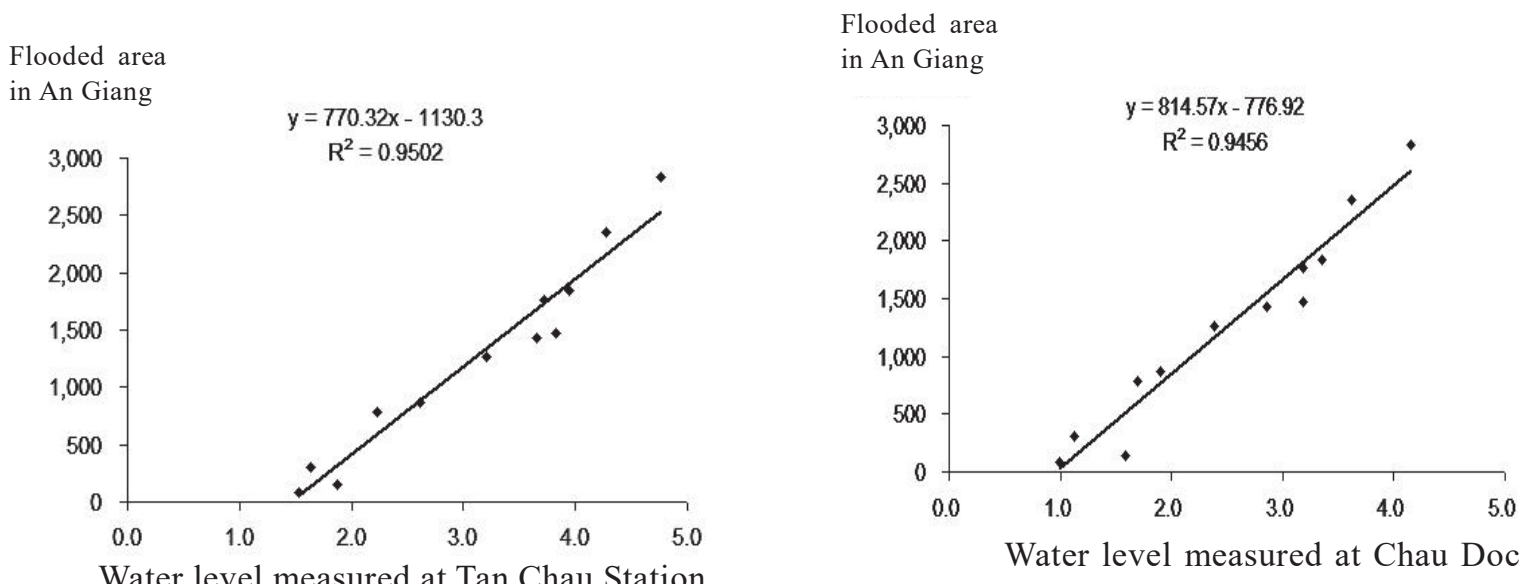

Fig.5 The correlation between the flooded area of An Giang province and the water elevation measured at Tan Chau and Chau Doc stations in 2015

There is a good correlation between the water elevation measured at Tan Chau and Chau Doc stations and the flooded area at the same time in An Giang province. The results verified the coefficient $\mathrm{R} 2$ over the years respectively as 0.84 and $0.84(2013), \mathrm{R} 2=0.87$ and $\mathrm{R} 2$ $=0.84$ (2014) and $\mathrm{R} 2=0.95$ and $\mathrm{R} 2=0,94$ (2015). With relatively high coefficient R2, it demonstrates that these two values are proportional to each other, when the water elevation gets higher, the flooded area will increase and vice versa. This is particularly significant in assessing the flooding depth by the

flooded area of the study area at a certain time.

\subsubsection{Start date, end date and prolonged time of} floods

The spatial distribution of start dates is changed in each year. The start date of floods in 2013 was earlier than floods in 2014 (Figure 6). For 2015, the start date along the Hau River and Mekong River was similar to 2013, however, in the marginal areas of flooded plains, especially in coastal areas near the Gulf of Thailand, the start date of 2015 was earlier than 2014.

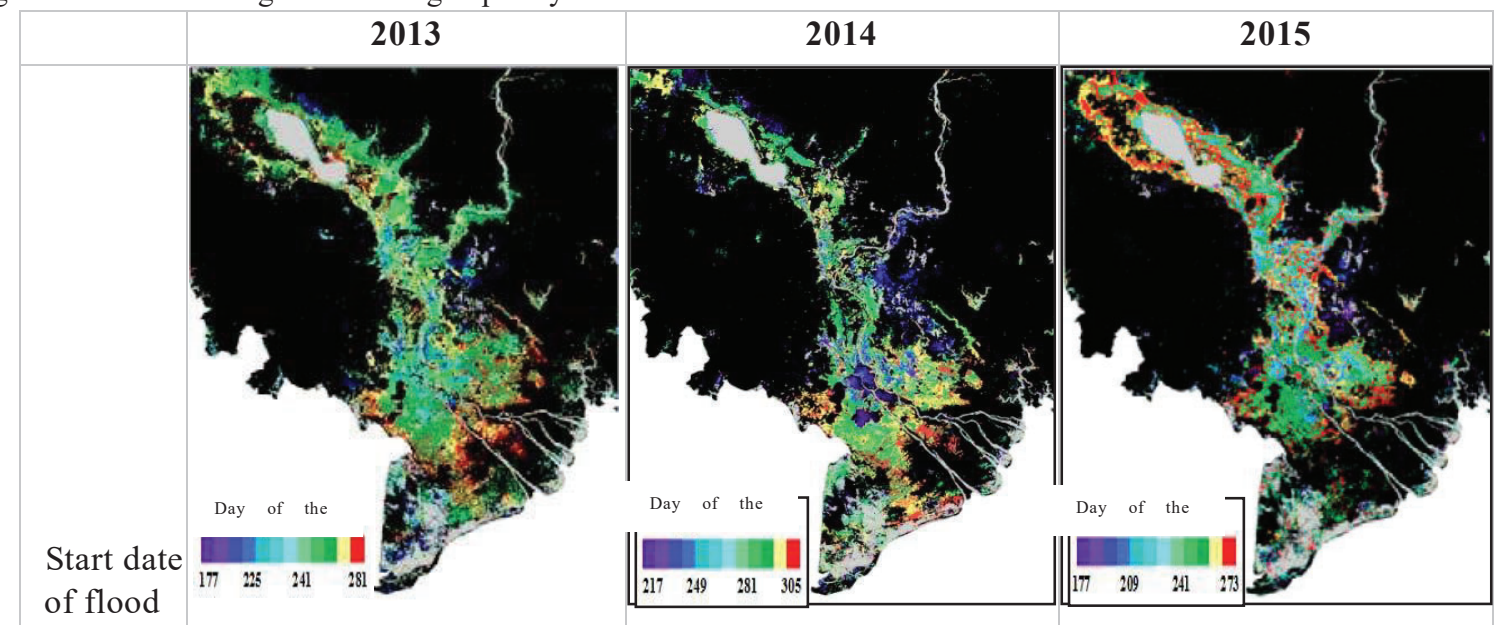




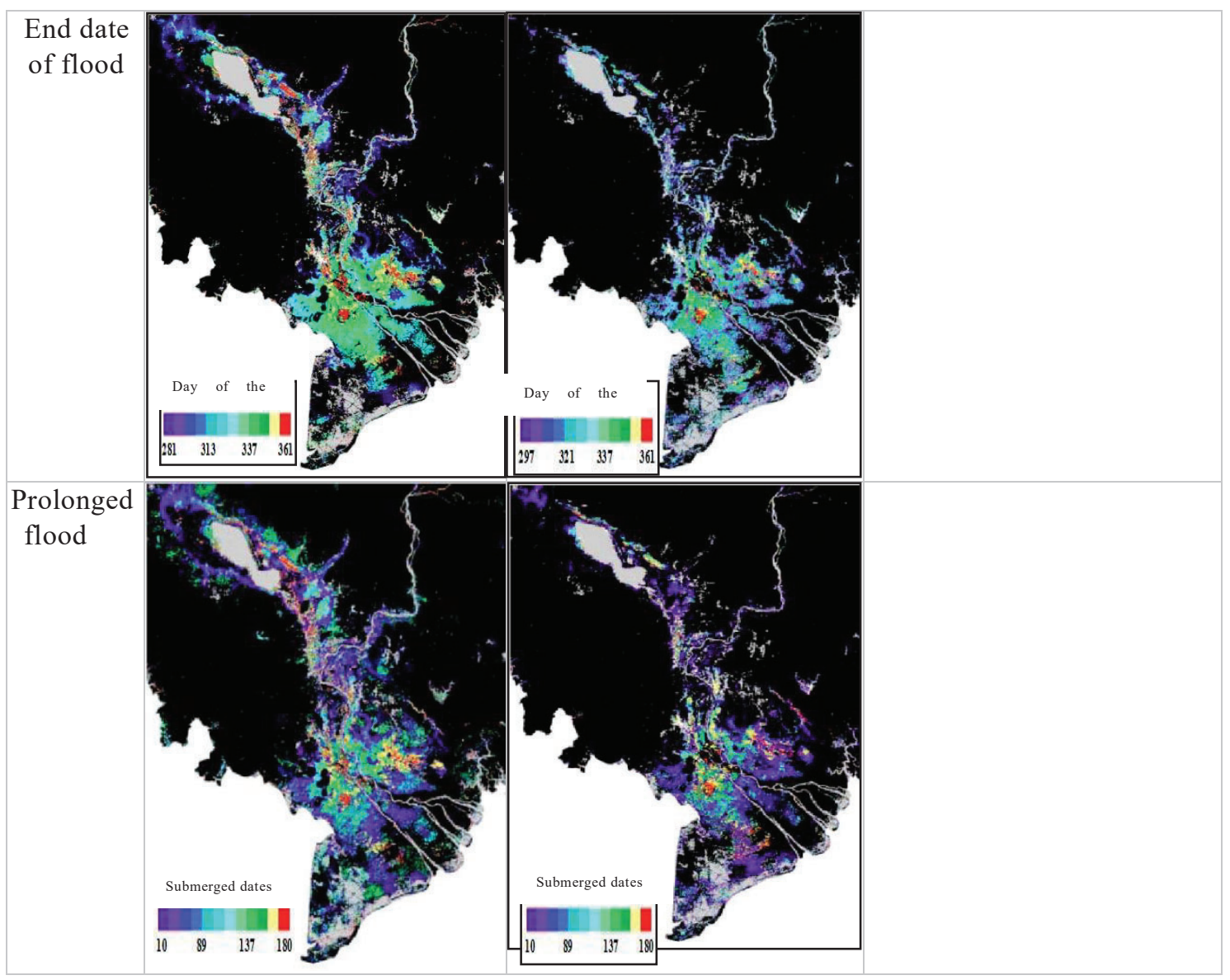

Fig.6 Start date, end date, prolonged time of floods

The flooding cycle over the years shows the lasting time of floods which is determined based on its start date and end date. For relatively large floods in 2013, it started earlier than the flood in 2014 and also ended later, which caused the prolonged flooding and difficulties in water irrigation and affected the sowing season. Floods in 2015 also started early and as estimated, the end time was also later than floods in 2014, which meant that a rather large area of agricultural land would be flooded.

\subsubsection{Compare the interpretation results of MODIS images with SPOT images}

MODIS image interpretation results need to be verified with the results interpreted from high resolution SPOT images. The research selected two representative images of An Giang province (dated $04^{\text {th }}$ December 2014) and Dong Thap (12 ${ }^{\text {th }}$ April 2013) as basis for comparison with MODIS images. The verification results taken of An Giang province are shown in Figure 7. 


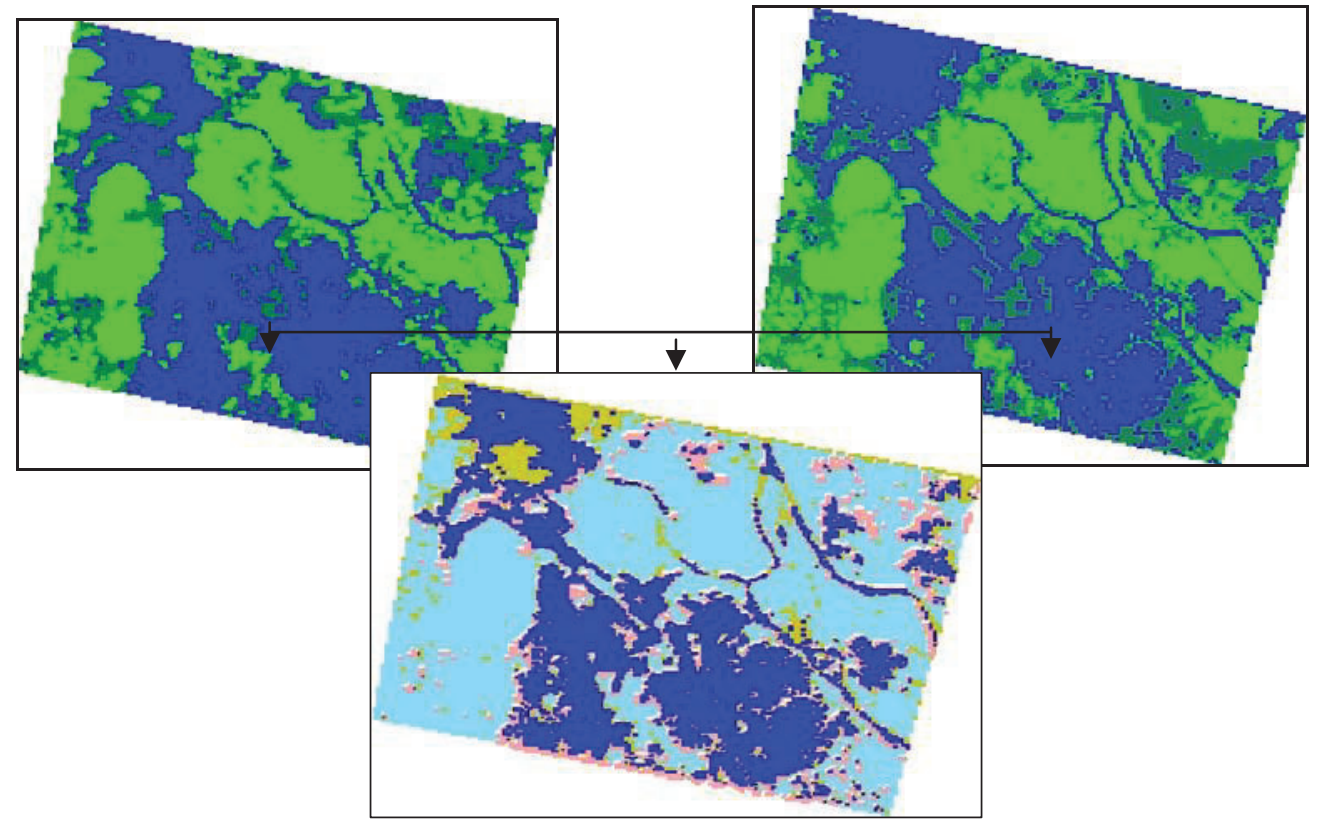

\section{Notation}

Flooded area in SPOT \& MODIS image
Common flooded area in both images

Flooded area only in SPOT image Flooded area only in MODIS image

Fig.7 Compare the results interpreted from MODIS and SPOT images for An Giang province (04th December 2014)

Results from comparing the two types of images of An Giang province showed a high level of compatibility (80\%). Dark blue area determined to be flooded had a great level of compatibility between the two images. The $\%$ rate of deviation (only in SPOT image or MODIS image) was negligible. Apart from the same area to be present in two different types of images, the different area only at MODIS images was relatively higher than the flood area interpreted only in SPOT image. This partly explained for the differences in resolution and how the different types of images caused the different results.

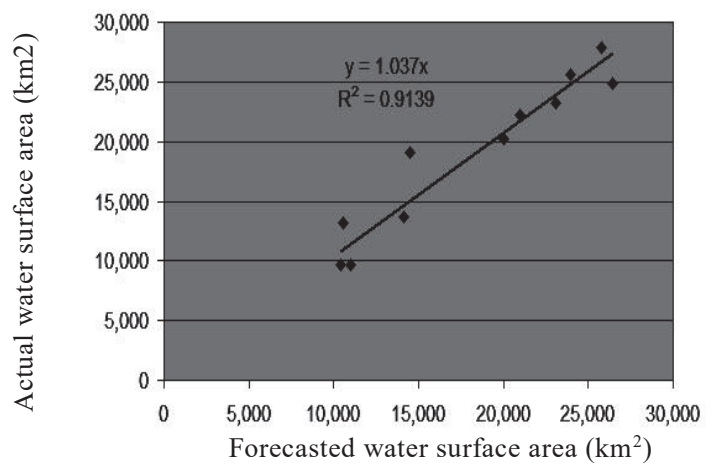

\subsection{Results of flood prediction for Mekong Delta}

The implementation process was divided into 11 stages from 4th July 2015 to 30th September 2015, corresponding to 11 results from the actual verification. Correlated results between the predicted flooded area and actual flooded area interpreted from MODIS images shows a relatively high correlation coefficient $(\mathrm{R} 2=0.91)$. The figure 8 shows that the degree of deviation in the forecasts is negligible and completely acceptable. This proves that the application of MODIS images in flood prediction in combination with other data is relatively accurate at flood events.

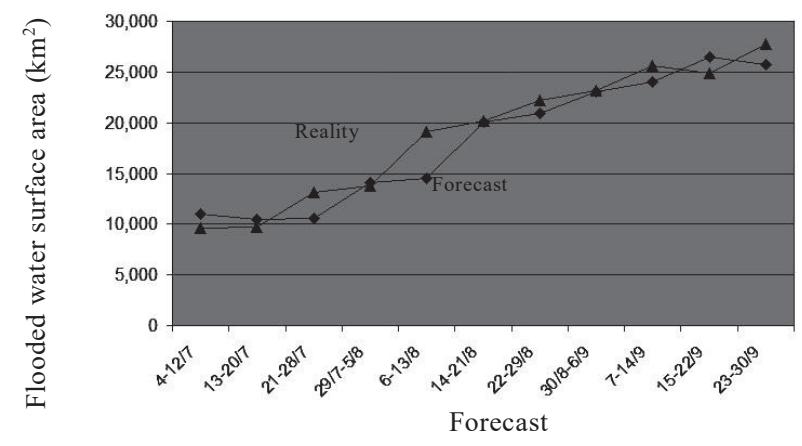

Fig.8 Correlation and deviation between the predicted flooded area and actual flooded area 


\section{CONCLUSIONS}

Based on the results above, the possibility of MODIS remote sensing images (MOD13) in monitoring the progress of floods in Mekong River Basin is pretty good. There is a relationship between characteristics of pixels and the spatial and temporal distribution of floods in Mekong River Basin. The high precision of analysis results indicates a possibility of widespread application of MOD13 images in monitoring, observing the flood progress as well as forecasting the floods in a long and contiguous time for a region as wide as a nation or territories. With the precision of approximately $91 \%$, the forecasting methods can be applied to predict the likelihood of floods in Mekong Delta region and the temporal limit for prediction is one week.

While the MODIS images are not costly as today, together with the gradual improvement of forecasting methods, this can be seen as an effective solution for monitoring and forecasting the flood and disasters.

\section{REFERENCES}

LV T T, Sun X Y,Liu C and Zhou X. 2014. Study on basic agricultural information extraction of Combodia based on MODIS data. Guangdong Agricultural Sciences, Vol. 050, pp. 198-203, doi: https://oi : 10.16768/j.issn.1004-874x.2014.03.050.

K.,TONG G Q and LI H M.2010. Simulation of climate change on the impact of the lower Mekong flood pulse. Express Water Resources \& Hydropower Information, Vol.31,pp.5-8,doi: https://doi

10.15974/j.cnki.slsdkb.2010.08.002.

ZHONG H P and WANG J S.2011. An analysis of Mekong River run off change an ditsimpact. Hydro-Science and Engineering, Vol.11,pp.48-52,doi: https://doi: 10.16198/j.cnki.1009-640x.2011.03.011.

ZHEN G W.2011. Effect of sea level rise on the Mekong
Delta. Express Water Resources \& Hydropower Information,Vol.32,pp.35-38,doi: https://doi : 10.15974/j.cnki.slsdkb.2011.05.001.

PENG D Z,GUO S L,HUANG Y F and ZHANG H.2004. Flood disaster monitoring and assessing system based on MODIS and GIS. Engineering Journal of Wuhan University, Vol.34, pp.7-10+31, http://kns.cnki.net/KCMS/detail/detail.aspx?dbcode $=\mathrm{CJF}$ Q\&dbname $=$ CJFD2004\&filename $=$ WSDD200404002\&v =MzA0MTN5emxWYi9MTWo3UGFyRzRIdFhNcTQ5R lpvUjhlWDFMdXhZUzdEaDFUM3FUcldNMUZyQ1VS TEtlWitSc0Y=

Sakamoto, T., Nguyen, N. V., Kotera, A., Ohno, H., Ishitsuka, N., and Yokozawa, M. (2007), Detecting temporal changes in the extent of annual flooding within the Cambodia and the Vietnamese Mekong Delta from MODIS time-series imagery, Remote Sensing of Environment, Vol.109,pp. 295-313, doi: http://dx.doi.org/10.1016/j.rse.2007.01.011.

Thenkabail, P. S., Schull, M., and Turral, H. (2005), Ganges and Indus river basin land use/land cover (LULC) and irrigated area mapping using continuous streams of MODIS data, Remote Sensing of Environment, Vol.95, pp.317-341, doi: https://doi.org/10.1016/j.rse.2004.12.018

Xiao, X., Bole S., Liu J., Zhuang D. (2005), “Mapping paddy rice agriculture in southern China using multi-temporal MODIS images", Remote Sensing of Environment , Vol.95, pp. 480-492, doi: https://doi.org/10.1016/j.rse.2004.12.009.

Xiao, X., Boles, S., Frolking, S., Li, C., Bau, J. Y., and Salas, W. (2006). Mapping paddy rice agriculture in South and Southeast Asia using multitemporal MODIS images. Remote Sensing of Environment, Vol.100, pp.95-113, doi: 